\title{
Seroprevalence of Jamestown Canyon virus in the Japanese general population
}

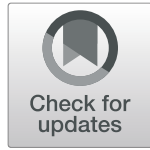

Hirofumi Kato', Masaaki Satoh', Madoka Kawahara', Satoshi Kitaura', Tomoki Yoshikawa', Shuetsu Fukushi', Kristina Dimitrova ${ }^{2}$, Heidi Wood ${ }^{2}$, Masayuki Saijo ${ }^{1}$ and Mutsuyo Takayama-Ito ${ }^{*^{*}}$ (D)

\begin{abstract}
Background: Jamestown Canyon virus (JCV) is a mosquito-borne orthobunyavirus that causes acute febrile illness, meningitis, and meningoencephalitis, mainly among adults. JCV is widely distributed in North America and the number of JCV cases in the U.S. has increased in recent years. Therefore, the central nervous system disease caused by JCV can be considered a potentially re-emerging viral disease. However, the seroprevalence of JCV is unknown in Japan. The purpose of this study is to evaluate the seroprevalence of JCV in the Japanese population.
\end{abstract}

Methods: We used an IgG enzyme-linked immunosorbent assay (IgG-ELISA) with JCV-infected cell-lysates and/or a neutralizing (NT) antibody assay. The cut-off value of IgG-ELISA was determined using IgG-ELISA to analyze serum specimens from 37 healthy Japanese donors. IgG-ELISA was validated by assessing its sensitivity and specificity, using 38 human serum samples previously tested for the presence or absence of antibodies against JCV and snowshoe hare virus (SSHV), in an in-house NT antibody assay conducted by the Public Health Agency of Canada. The seroepidemiological study was performed using IgG-ELISA and NT antibody assay to analyze 246 human serum samples from the serum bank of the National Institute of Infectious Diseases (NIID) in Japan.

Results: The cut-off value of IgG-ELISA was determined at 0.20, based on the mean (-0.075) and standard deviation (0.092) values using Japanese donors' sera. The sensitivity and the specificity of IgG-ELISA determined using 25 JCV-positive and 4 JCV-negative serum samples were 96 and 100\%, respectively. Analysis of the 246 Japanese serum samples revealed that no specimen showed a higher value than the cut-off value of IgG-ELISA, and no sample tested positive by the NT antibody assay.

Conclusions: Our results showed that JCV is not circulating significantly in Japan. To the best of our knowledge, this is the first report to demonstrate the seroprevalence of JCV in the general population in Japan.

Keywords: Jamestown canyon virus, Snowshoe hare virus, California serogroup, Seroepidemiology, Orthobunyavirus, Encephalitis, Japan

\section{Background}

Jamestown Canyon virus (JCV) belongs to the genus Orthobunyavirus in the family Peribunyaviridae of the order Bunyavirales [1]. JCV causes acute febrile illness and sometimes central nervous infections such as

\footnotetext{
* Correspondence: mutsuito@niid.go.jp

${ }^{1}$ Department of Virology 1, National Institute of Infectious Diseases, 1-23-1 Toyama, Shinjuku-ku, Tokyo 162-8640, Japan

Full list of author information is available at the end of the article
}

meningitis and meningoencephalitis, mainly among adults [2, 3]. JCV is classified into the California serogroup (CSG), along with La Crosse virus (LACV), snowshoe hare virus (SSHV), Inkoo virus (INKV), and Tahyna virus (TAHV) [4]. CSG viruses contain trisegmented, negative sense RNA genomes [5]. The serogroup is worldwide prevalent and includes human pathogens such as LACV and SSHV in North America; INKV and TAHV in Asia and Europe; Guaroa virus in

(c) The Author(s). 2020 Open Access This article is licensed under a Creative Commons Attribution 4.0 International License, which permits use, sharing, adaptation, distribution and reproduction in any medium or format, as long as you give appropriate credit to the original author(s) and the source, provide a link to the Creative Commons licence, and indicate if changes were made. The images or other third party material in this article are included in the article's Creative Commons licence, unless indicated otherwise in a credit line to the material. If material is not included in the article's Creative Commons licence and your intended use is not permitted by statutory regulation or exceeds the permitted use, you will need to obtain permission directly from the copyright holder. To view a copy of this licence, visit http://creativecommons.org/licenses/by/4.0/ The Creative Commons Public Domain Dedication waiver (http://creativecommons.org/publicdomain/zero/1.0/) applies to the data made available in this article, unless otherwise stated in a credit line to the data. 
North and South America; and Lumbo virus in Africa [6]. CSG viruses use mosquito vectors, primarily species from the Aedes and Ochlerotatus genera. The mammalian host species include small rodents for SSHV, LACV, and TAHV; hares for SSHV, TAHV, and INKV; and deer for JCV [5, 7]. Currently, there are no available vaccines or specific treatments against CSG viruses.

JCV was first isolated from Culiseta inornata mosquitoes at Jamestown Canyon, Colorado, in the United States in 1961 [8]. JCV is widely prevalent in North America. Until 2012, 0-3 JCV cases had been reported in the U.S. However, this number increased to 75 and 41 cases in US northern states in 2017 and 2018, respectively $[9,10]$. In addition, the ratio of symptomatic to asymptomatic individuals is speculated to be in the range of 1:100 to 1:1500 [11]. These data suggest that JCV can be considered a potentially re-emerging virus. The main vectors and reservoirs of JCV include mosquito species from the Aedes, Coquillettidia, Culex, and Culiseta genera [12, 13], and white-tail deer [14], respectively.

CSG viruses, including JCV, have not been isolated from mosquitoes or mammals in Japan. To date, no CSG infection cases have been reported in Japan. However, a nationwide study on mosquito distribution revealed that Aedes, Culex, and Culiseta are widely distributed in Japan [15]. Since deer, horses, and goats inhabit Japan and can act as reservoirs in the JCV lifecycle, there is a potential risk for the establishment of the JCV lifecycle in Japan. Mosquito-borne viral infections in humans have increased gradually worldwide, since global warming affects the geographical distribution and activity of mosquitoes. In fact, the 2015 dengue fever outbreak in Tokyo occurred as an autochthonous transmission of dengue virus, after 70 years from the last dengue fever outbreak in Japan after World War II [16]. Thus, mosquito-borne diseases became a public health threat in Japan and in disease-free areas. Although JCV infection cases have not been investigated to date, surveillance for mosquito-borne orthobunyavirus diseases is recommended.

To evaluate the prevalence of JCV in Japan, we developed an IgG enzyme-linked immunosorbent assay (IgG-ELISA) using JCV-infected cell-lysates as antigens and human serum specimens to conduct a serological survey among the residents of Japan.

\section{Methods}

\section{Cells and viruses}

Vero cells and Huh-7 cells were purchased from ATCC (\# CCL-819) and BIKEN, Osaka University, respectively. All cells were grown in Dulbecco's modified Eagle medium (DMEM; Sigma-Aldrich, St. Louis, MO) supplemented with $5 \%$ heat-inactivated fetal bovine serum (FBS; Biowest, Nuaille, France), non-essential amino acids (Sigma-Aldrich), and antibiotics (100 U/mL penicillin and $100 \mu \mathrm{g} / \mathrm{mL}$ streptomycin; Thermo Fisher Scientific, Waltham, MA). The JCV $61 \mathrm{~V}-2235$ strain was purchased from ATCC (VR-712).

\section{Serum samples}

Serum samples obtained from 37 healthy Japanese donors, which were negative in the NT assay, were used as negative controls to establish the cut-off value of IgG-ELISA. Forty human serum samples, which were stored at the Zoonotic Diseases and Special Pathogens Division, Public Health Agency of Canada, were tested for the presence or absence of JCV and SSHV, during an in-house neutralizing (NT) antibody assay conducted by the Public Health Agency of Canada [17]. Two additional specimens with an NT antibody titer against JCV equal to that against SSHV were excluded. The 38 specimens were classified into five groups as follows: group 1: JCV- and SSHV-positive, with an NT antibody titer against JCV 4-fold higher than that against SSHV (10 samples); group 2: JCV-positive and SSHVnegative (15 samples); group 3: JCV- and SSHV-positive, and an NT antibody titer against JCV inferior (4-fold) to that against SSHV (5 samples); group 4: JCV-negative and SSHV-positive (4 samples); group 5: JCV- and SSHVnegative (4 samples). Individuals from groups 1 and 2, 3 and 4 , and 5 were diagnosed with JCV-positive, SSHVpositive, and negative, respectively. Several thousands of volunteers' serum samples from all over Japan are stored in the serum bank of the National Institute of Infectious Diseases (NIID) in Japan when annual national epidemiological surveillance of vaccine-preventable diseases is performed. The serum samples stored in the serum bank were collected mostly from children, and has limited samples from adults, especially elderly people (more than 65 years old). Among these, serum samples used in this study were selected from those obtained and stored between 2011 and 2016. The proportions of age, sex, and regions of the blood donors were matched with the same proportions of the general population in Japan, based on the statistics published by the Statistics Bureau of Japan [18]. Sample size was calculated using Stata 13 software for Windows (StataCorp LP, College Station, TX), based on an estimated seroprevalence of $20 \%$ among the Japanese population with an interval width of 0.10 (upper 0.05 , lower 0.05 ) and a confidential level of $95 \%$ [17], along with considering limited available samples the serum bank can prepared. According to the calculation, a total of 246 Japanese specimens from the serum bank were tested. All samples were inactivated at $56^{\circ} \mathrm{C}$ for $30 \mathrm{~min}$ in a water bath.

\section{IgG-ELISA for detecting antibodies against JCV}

JCV-positive and JCV-negative antigens were prepared as follows: Huh-7 cells infected with JCV at a multiplicity of infection of 0.05 and mock-infected Huh-7 cells 
were cultured for 2 days at $37^{\circ} \mathrm{C}$ and $5 \% \mathrm{CO} 2$ saturation in maintenance medium, consisting of DMEM containing 2\% FBS (DMEM-2FBS). The virus- and mockinfected cells were washed with phosphate-buffered saline solution (PBS) and soaked for $20 \mathrm{~min}$ in PBS containing $1 \%$ Nonidet P-40. Lysates were centrifuged at $4000 \mathrm{rpm}$ for $10 \mathrm{~min}$. The supernatant fractions of the virus- and mock-infected cell solutions were used as JCV-positive and JCV-negative antigens, respectively. ELISA was performed as described elsewhere with minor modifications [19, 20]. Briefly, 96-well plates (NuncImmuno $^{\text {Tx }}$ Plate, Thermo Fisher Scientific, Waltham, MA) were coated with JCV-positive and JCV-negative antigens at $4{ }^{\circ} \mathrm{C}$ overnight, then incubated at $18-25^{\circ} \mathrm{C}$ for $2 \mathrm{~h}$ with heat-inactivated sera from the enrolled individuals, which were diluted 4-fold from 1:100 to $1: 6400$ as previously reported [21, 22]. Plates were washed thrice with $0.05 \%$ Tween-20 with PBS (PBST), then incubated with a 1:2000 diluted by blocking buffer of horseradish peroxidase (HRP)-conjugated goat anti-human IgG (goat anti-human IgG $(\mathrm{H}+\mathrm{L})$ crossabsorbed secondary antibody, HRP; Thermo Fisher Scientific) at $37^{\circ} \mathrm{C}$ for $1 \mathrm{~h}$. Plates were washed thrice with PBST and incubated with $100 \mu \mathrm{L}$ of substrate solution (ELISA POD Substrate TMB Kit, Popular; Nacalai Tesque, Kyoto, Japan) at $18-25^{\circ} \mathrm{C}$ for $4 \mathrm{~min}$. The enzyme reaction was terminated using $100 \mu \mathrm{L}$ of $1 \mathrm{M}$ sulfuric acid. The absorbance (optical density, OD) was measured at a wavelength of $450 \mathrm{~nm}$ $\left(\mathrm{OD}_{450}\right)$ using a microplate reader (iMark, Bio-Rad Laboratories Inc., Hercules, $\mathrm{CA}$ ). The $\mathrm{OD}_{450}$ values of negative antigen wells were subtracted from the $\mathrm{OD}_{450}$ values from the corresponding positive antigen samples. The cut-off value was set as the average value plus three times standard deviation $(\mathrm{SD})$ of the control sera from Japanese donors' sera. Samples were considered IgG-ELISA positive if it yielded an $\mathrm{OD}_{450}$ value above the cut-off value.

\section{Neutralization assay}

An NT assay was carried out as previously described with minor modifications [17]. Briefly, serum samples were heat-inactivated at $56^{\circ} \mathrm{C}$ for $30 \mathrm{~min}$, then diluted 10-fold with DMEM-2FBS. Subsequently, $75 \mu \mathrm{L}$ of each dilution was mixed with a same volume of DMEM-2FBS containing $100 \quad 50 \%$ tissue culture infectious dose $\left(\mathrm{TCID}_{50}\right)$ of JCV, then incubated at $37{ }^{\circ} \mathrm{C}$ for $1 \mathrm{~h}$. Thereafter, $100 \mu \mathrm{L}$ of these mixtures were used to inoculate Vero cell monolayers, then cultured at $37^{\circ} \mathrm{C}$ for 5 days. After incubation, cells were fixed with $10 \%$ formalin for $1 \mathrm{~h}$, then stained with methylene blue solution. After washing with distilled water, cytopathic effects were observed.

\section{Statistical analysis}

The Mann-Whitney $U$ test was used to compare $\mathrm{OD}_{450}$ values from IgG-ELISA in each group of human sera. The non-parametric Spearman rank correlation coefficient was used to evaluate the relationship between $\mathrm{OD}_{450}$ values and titers of JCV and SSHV NT antibodies. All $p$-values were two-sided, and $p<0.05$ was considered significant; $\mathrm{p}$-values were corrected by Bonferroni adjustments when multiple comparisons were implemented. All data were analyzed using GraphPad Prism 8 for Windows (GraphPad Software Inc., San Diego, CA).

\section{Results}

Determination of the cut-off value of IgG-ELISA using sera from Japanese healthy donors

The $\mathrm{OD}_{450}$ value of 4 -fold serially diluted serum specimens from 37 Japanese donors was measured to determine the cut-off of IgG-ELISA. We found that the cut-off was 0.20 , based on the mean $(-0.075)$ and SD (0.092) values.

\section{Determination of the sensitivity and specificity of the JCV-antigen-based IgG-ELISA}

The sensitivity and specificity of IgG-ELISA were assessed using the 38 sera provided by the Public Health Agency of Canada (Fig. 1a). We found that 24 of the 25 specimens classified as group 1 or 2 (JCV-positive) tested positive by IgG-ELISA, whereas all 4 samples from group 5 (SSHV-negative) tested negative for JCV. Therefore, the sensitivity and specificity were calculated as 96 and 100\%, respectively. On the other hand, 4 samples of the 9 specimens from groups 3 and 4 (SSHVpositive) tested positive for JCV, showing a $44 \%$ crossreactivity with antibodies against SSHV. The $\mathrm{OD}_{450}$ values in groups 1 and 2 were significantly higher than those observed in the other groups and in group 5, respectively.

\section{Comparison between $\mathrm{OD}_{450}$ values from IgG-ELISA and neutralization antibody titers}

To evaluate the relationship between IgG-ELISA and NT antibody titers, a statistical comparison was performed between $\mathrm{OD}_{450}$ values from IgG-ELISA and antibody titers from the neutralization test. Our results showed a nearly linear relationship between $\mathrm{OD}_{450}$ values and NT antibody titers against JCV (Spearman's correlation coefficient of $0.652(p<0.0001))$ (Fig. 1b). In contrast, no correlation was found between $\mathrm{OD}_{450}$ values and NT antibody titers against SSHV (Spearman's correlation coefficient of $-0.411(p=0.081)$ ) (Fig. 1c). 


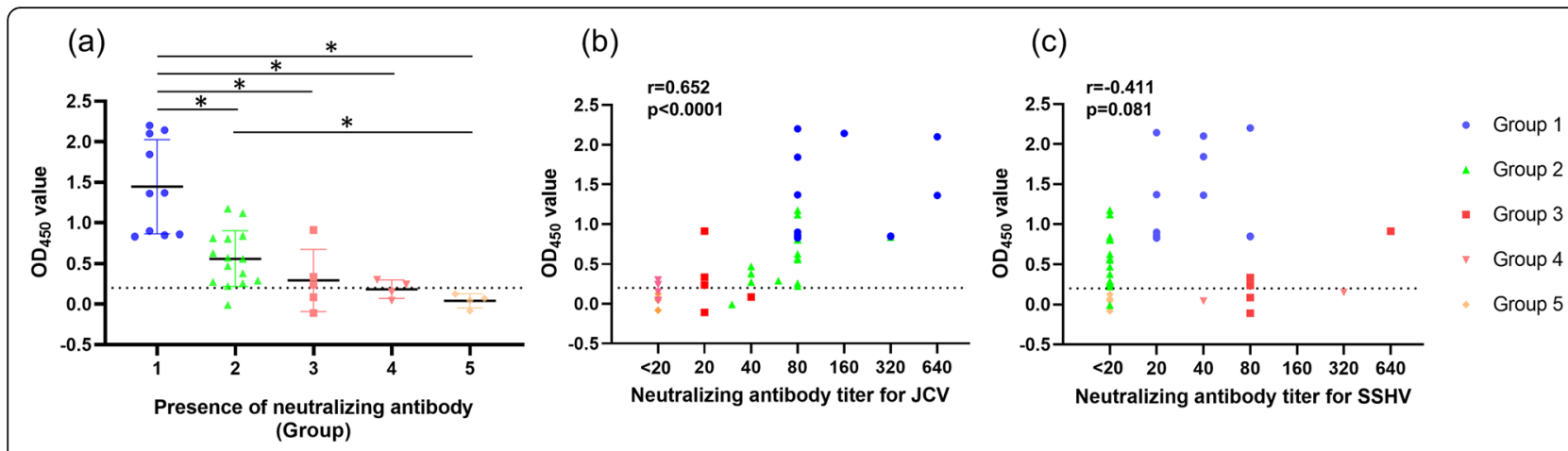

Fig. 1 Comparison of IgG-ELISA and NT antibody assay for detecting JCV in human sera. a Spectrophotometric results for assessing the specificity and sensitivity of IgG-ELISA for detecting JCV in human sera. The 38 specimens were classified into 5 groups based on previous results; group 1: JCV and SSHV both-positive and NT antibody titer for JCV was higher than that for SSHV (10 samples); group 2: JCV-positive and SSHV-negative (15 samples); group 3: both-positive and NT antibody titer for JCV was less than that for SSHV (5 samples); group 4: JCV-negative and SSHVpositive (4 samples); group 5: both-negative (4 samples). b, c Comparison between IgG-ELISA OD 450 values and neutralization antibody titers for JCV and SSHV. Statistical analyses were performed using the Mann-Whitney U test and Spearman's rank correlation. Asterisks indicate $p<0.005$

\section{Seroprevalence of antibodies against JCV among the Japanese population}

The number and characteristics of samples (age, sex, and regions) are shown in Table 1. A total of 246 Japanese specimens from the serum bank were tested using IgG-ELISA and NT antibody assay. No sample showed a positive reaction by IgG-ELISA or NT assay.

\section{Discussion}

Humans get infected with JCV primarily through the mosquito bite belonging to the genera Ochlerotatus, Aedes, Coquillettidia, Culex, and Culiseta [5, 7]. Mammalian host species such as white-tailed deer, mule deer, sika deer, sheep, horses, goats, etc. serve as reservoirs for the virus [6]. Since deer, horses, and goats that inhabit Japan can act as reservoirs in the JCV lifecycle, there is a potential risk of JCV spreading in Japan. A study conducted in Nova Scotia, Canada, using human sera for unrelated diagnosis, revealed a seropositivity of $21.2 \%$ for JCV [17]. Additionally, in a seroprevalence study conducted in Quebec, Canada, 9-24\% tested individuals were positive for JCV [23]. On the basis of these surveys, it is estimated that one fourth of the population in endemic areas has antibodies against JCV. Conversely, the results from our study using JCV-antigen-based IgGELISA with a high sensitivity and specificity showed that none of the 246 analyzed samples from Japan tested positive, suggesting that JCV infection does not exist in Japan at least as frequently as in some endemic areas, given the number of samples tested.

In China, TAHV was isolated from Culex spp. mosquitoes collected in the Xinjiang Uygur Autonomous Region, and TAHV antibodies were detected in human samples [24]. Accordingly, we first speculated that CSG viruses might have spread widely in East Asian countries, including Japan. CSG viruses are known to exhibit serological cross-reactivity [25]. Additionally, the detection of anti-JCV IgM using ELISA may indicate infection by other CSG viruses [2, 26]. The JCV-IgG ELISA developed in this study showed only a partial cross-reactivity (44\%) with antibodies against SSHV. Although crossreactivity against only SSHV was investigated in this study, further evaluations on cross-reactivity against other CSG viruses are also required in the JCV-IgG ELIS A. Considering the seroepidemiological results, imported cases of CSG viruses into Japan should be monitored. It

Table 1 Number and characteristics of samples by age and regions

\begin{tabular}{lllllllll}
\hline $\begin{array}{l}\text { Region } \\
\text { Age (years) }\end{array}$ & $\begin{array}{l}\text { Hokkaido/ } \\
\text { Tohoku }\end{array}$ & Kanto & Chubu & Kinki & Chugoku & Shikoku & Kyushu & Total \\
\hline $0-19$ & 6 & 14 & 8 & 8 & 4 & 2 & 46 \\
$20-39$ & 6 & 18 & 8 & 10 & 4 & 2 & 56 \\
$40-59$ & 8 & 22 & 10 & 12 & 4 & 2 & 8 & 76 \\
$60-$ & 8 & 26 & 14 & 14 & 4 & 2 & 10 & 78 \\
Total & 28 & 80 & 40 & 44 & 16 & 8 & 246 \\
\hline
\end{tabular}

Specimens were provided by the serum bank of the National Institute of Infectious Diseases in Japan. The number of males and females is equal. The main cities

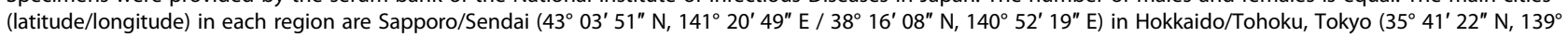

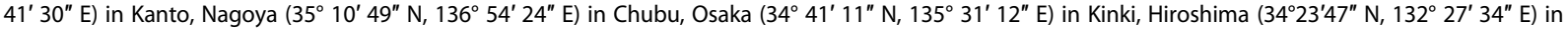
Chugoku, Takamatsu ( $34^{\circ} 20^{\prime} 25^{\prime \prime} \mathrm{N}, 134^{\circ} 02^{\prime} 36^{\prime \prime}$ E) in Shikoku, and Fukuoka ( $\left.33^{\circ} 36^{\prime} 23^{\prime \prime} \mathrm{N}, 130^{\circ} 25^{\prime} 05^{\prime \prime} \mathrm{E}\right)$ in Kyushu 
is noteworthy that infection with CSG viruses should be considered as a differential diagnosis in patients returning from endemic areas, with a history of mosquito-bite and unknown encephalitis. Hereafter, an early outbreak detection system based on a risk assessment approach would be required, by implementing a surveillance program for detecting antibodies against JCV in animal sera and mosquitoes.

In this study, JCV-infected cell-lysates were used as antigens for IgG-ELISA. It has been reported that the sensitivity and specificity of ELISA for flaviviruses from Vero cell-lysates were lower than those observed using a recombinant protein-based ELISA, possibly due to impurities from cell-lysates [27]. However, the JCV-antigen IgG-ELISA showed high sensitivity and specificity. Additionally, we evaluated the presence of antibodies against JCV using an NT antibody assay. No Japanese serum sample tested positive by ELISA or NT antibody assay. Based on these data, we consider that the possibility of a wide distribution of JCV in Japan is lower than initially hypothesized.

Notably, the $\mathrm{OD}_{450}$ values of samples from groups 1 and 2 tested by IgG-ELISA were higher than those found in samples from groups 3 and 4 diagnosed with SSHV. Besides, we found a nearly linear relationship between $\mathrm{OD}_{450}$ values and NT antibody titers against JCV. Since the $\mathrm{OD}_{450}$ values can increase owing to the presence of NT antibodies against SSHV, IgG-ELISA might not be as efficient as the NT antibody test in distinguishing between JCV and SSHV completely, especially at border line from 0.2 to 1.0 of the $\mathrm{OD}_{450}$ values. Nevertheless, IgG-ELISA can be used to diagnose JCV without a neutralizing assay when $\mathrm{OD}_{450}$ values shows more than 1.0.

A limitation of this study could be a biased selection of samples because the samples from the serum bank of NIID were provided by volunteers and not selected by random sampling. Furthermore, it is possible that the true prevalence of JCV might be less than the detection limit because of the small number of samples used in the current study. Although several thousands of volunteers' serum samples have been stored in the serum bank of NIID, we could not freely use these samples because of finite scientific resources. Moreover, the serum bank has limited samples from adults, especially elderly people (more than 65 years old), since most samples have been collected from children to investigate the prevalence of vaccine-preventable diseases.

\section{Conclusions}

Our results showed that JCV is not circulating significantly in Japan. To the best of our knowledge, this is the first report demonstrating JCV seroprevalence in the general population in Japan.

\section{Abbreviations}

ELISA: Enzyme-linked immunosorbent assay; IgG: Immunoglobulin G; FBS: Fetal bovine serum; DMEM: Dulbecco's modified eagle medium; ATCC: American type culture collection; NT: Neutralizing; NIID: National institute of infectious diseases; OD: Optical density; SD: Standard deviation; CSG: California serogroup; JC: Jamestown Canyon; LACV: La Crosse virus; SSHV: Snowshoe hare virus; INKV: Inkoo virus; TAHV: Tahyna virus

\section{Acknowledgements}

We would like to thank Dr. Satoru Arai and Dr. Keiko Tanaka-Taya from the serum bank of NIID, for kindly providing us with sera from Japanese individuals.

\section{Authors' contributions}

Study conception and design: HK, MS2 (M, Saijo), MI. Data curation: HK. Funding acquisition: MI. Investigation: HK, MS1 (M,Satoh), MK, SK, KD, HW. Methodology: HK, MS1, TY, SF, MS2, MI. Supervision: MS2, MI. Visualization: HK. Writing original draft: HK. Writing review and editing: MS2, MI. All authors read and approved the final manuscript.

\section{Funding}

This work was partially supported by the Japan Agency for Medical Research and Development (AMED), under grant numbers 17fk0108108j0601,

$18 \mathrm{fk} 0108035 \mathrm{j} 0602$, and 19fk0108035j0603.

\section{Availability of data and materials}

The datasets used and analysed during the current study are available from the corresponding author on reasonable request.

\section{Ethics approval and consent to participate}

The research protocol for establishing the cut-off value of the ELISA using Japanese donors' sera, and the seroepidemiological protocol using sera from the serum bank of the National Institute of Infectious Diseases, Japan (NIID) were approved by the medical research ethics committee of the National Institute of Infectious Diseases for the use of human subjects (approval no. 1097 and 1069). Before sample collection, written informed consent was obtained from the participants or the participants' parents. The personal information of clinical specimens was masked. All personal information was anonymised, and no data allowing individual identification was retained. This study was carried out according to the principles expressed in the Declaration of Helsinki.

\section{Consent for publication}

Not applicable.

\section{Competing interests}

The authors have declared that no competing interests exist.

\section{Author details}

${ }^{1}$ Department of Virology 1, National Institute of Infectious Diseases, 1-23-1 Toyama, Shinjuku-ku, Tokyo 162-8640, Japan. ${ }^{2}$ Zoonotic Diseases and Special Pathogens Division, Public Health Agency of Canada, 1015 Arlington Street Winnipeg, Winnipeg, Manitoba R3E 3R2, Canada.

Received: 7 July 2020 Accepted: 16 October 2020

Published online: 23 October 2020

\section{References}

1. Abudurexiti A, Adkins S, Alioto D, Alkhovsky SV, Avšič-Županc T, Ballinger MJ, et al. Taxonomy of the order Bunyavirales: update 2019. Arch Virol. 2019; 164(7):1949-65.

2. Pastula DM, Hoang Johnson DK, Fischer M, White JL, Staples JE, Dupuis AP. Jamestown canyon virus disease in the United States-2000-2013. Am J Trop Med Hyg. 2015;93(2):384-9.

3. Matkovic E, Hoang Johnson DK, Staples JE, Mora-Pinzon MC, Elbadawi LI, Osborn RA, et al. Enhanced arboviral surveillance to increase detection of Jamestown canyon virus infections, Wisconsin, 2011-2016. Am J Trop Med Hyg. 2019;100(2):445-51.

4. Calisher $\mathrm{CH}$. Taxonomy, classification, and geographic distribution of California serogroup bunyaviruses. Prog Clin Biol Res. 1983;123:1-16. 
5. Evans $A B$, Peterson KE. Throw out the map: neuropathogenesis of the globally expanding California serogroup of orthobunyaviruses. Viruses. 2019;1 (9):794.

6. Bennett RS, Nelson JT, Gresko AK, Murphy BR, Whitehead SS. The full genome sequence of three strains of Jamestown canyon virus and their pathogenesis in mice or monkeys. Virol J. 2011;8(1):136.

7. Evans $A B$, Winkler CW, Peterson KE. Differences in neuropathogenesis of encephalitic California serogroup viruses. Emerg Infect Dis. 2019;25(4):728-38.

8. Pastula DM, Smith DE, Beckham JD, Tyler KL. Four emerging arboviral diseases in North America: Jamestown canyon, Powassan, chikungunya, and Zika virus diseases. J Neuro-Oncol. 2016;22(3):257-60.

9. Curren EJ, Lehman J, Kolsin J, Walker WL, Martin SW, Staples JE, et al. West Nile virus and other nationally notifiable arboviral diseases - United States, 2017. MMWR Morb Mortal Wkly Rep. 2018;67(41):1137-42.

10. McDonald E, Martin SW, Landry K, Gould CV, Lehman J, Fischer M, et al. West Nile virus and other domestic nationally notifiable arboviral diseases United States, 2018. MMWR Morb Mortal Wkly Rep. 2019;68(31):673-8.

11. Drebot MA. Emerging mosquito-borne bunyaviruses in Canada. Can Commun Dis Rep. 2015;41(6):117-23.

12. Anderson JF, Andreadis TG, Ferrandino FJ, Main AJ, Armstrong PM. Arboviruses in North Dakota, 2003-2006. Am J Trop Med Hyg. 2015;92(2):377-93.

13. Andreadis TG, Anderson JF, Armstrong PM, Main AJ. Isolations of Jamestown canyon virus (Bunyaviridae: Orthobunyavirus) from fieldcollected mosquitoes (Diptera: Culicidae) in Connecticut, USA: a ten-year analysis, 1997-2006. Vector Borne Zoonotic Dis. 2008;8(2):175-88.

14. Boromisa RD, Grimstad PR. Seroconversion rates to Jamestown canyon vrus among six populations of white-tailed deer (Odocoileus virginianus) in Indiana. J Wildl Dis. 1987;23(1):23-33.

15. Maekawa Y, Tsuda H, Sawabe K. A nationwide survey on distribution of mosquitoes in Japan. Med Entomol Zool. 2016;67(1):1-12.

16. Kutsuna S, Kato Y, Moi ML, Kotaki A, Ota M, Shinohara K, et al. Autochthonous dengue fever, Tokyo, Japan, 2014. Emerg Infect Dis. 2015;21(3):517-20.

17. Patriquin $G$, Drebot $M$, Cole T, Lindsay R, Schleihauf $E$, Johnston BL, et al. High seroprevalence of Jamestown canyon virus among deer and humans, Nova Scotia, Canada. Emerg Infect Dis. 2018;24(1):118-21.

18. Statistics Bureau of Japan. (1996) https://www.stat.go.jp/english/index.html. Accessed 18 May 2020.

19. Fukuma A, Fukushi S, Yoshikawa T, Tani H, Taniguchi S, Kurosu T, et al. Severe fever with thrombocytopenia syndrome virus antigen detection using monoclonal antibodies to the nucleocapsid protein. PLoS Negl Trop Dis. 2016;10(4):e0004595.

20. Satoh M, Kato H, Takayama-Ito M, Ogawa M, Ando S, Saijo M. In vitro evaluation of minimum inhibitory concentration of several antibacterial agents against rickettsia japonica using a plaque reduction assay system. $J$ Infect Chemother. 2019;25(11):917-9.

21. Saijo M, Georges-Courbot M-C, Marianneau P, Romanowski V, Fukushi S, Mizutani T, et al. Development of recombinant nucleoprotein-based diagnostic systems for Lassa fever. Clin Vaccine Immunol. 2007;14(9):1182-9.

22. Saijo M, Niikura M, Morikawa S, Ksiazek TG, Meyer RF, Peters CJ, et al. Enzymelinked immunosorbent assays for detection of antibodies to Ebola and Marburg viruses using recombinant nucleoproteins. J Clin Microbiol. 2001;39(1):1-7.

23. Sampasa-Kanyinga H, Lévesque B, Anassour-Laouan-Sidi E, Côté S, Serhir B Ward BJ, et al. Zoonotic infections in communities of the James Bay Cree territory: an overview of seroprevalence. Can J Infect Dis Med Microbiol. 2013;24(2):79-84.

24. Lu Z, Lu X-J, Fu S-H, Zhang S, Li Z-X, Yao X-H, et al. Tahyna virus and human infection. China Emerg Infect Dis. 2009;15(2):306-9.

25. Hubalek Z, Chanas AC, Johnson BK, Simpson DIH. Cross-neutralization study of seven California group (bunyaviridae) strains in homoiothermous (PS) and poikilothermous (XTC-2) vertebrate cells. J Gen Virol. 1979;42(2):357-62.

26. Karabatsos N, Mathews JH. Serological reactions of fractionated hamster immunoglobulins with California group viruses. Am J Trop Med Hyg. 1980 29(6):1420-7.

27. Ansari MZ, Shope RE, Malik S. Evaluation of vero cell lysate antigen for the ELISA of flaviviruses. J Clin Lab Anal. 1993;7(4):230-7.

\section{Publisher's Note}

Springer Nature remains neutral with regard to jurisdictional claims in published maps and institutional affiliations.

\section{Ready to submit your research? Choose BMC and benefit from:}

- fast, convenient online submission

- thorough peer review by experienced researchers in your field

- rapid publication on acceptance

- support for research data, including large and complex data types

- gold Open Access which fosters wider collaboration and increased citations

- maximum visibility for your research: over $100 \mathrm{M}$ website views per year

At BMC, research is always in progress.

Learn more biomedcentral.com/submissions 